\title{
CHANGING FLOW PATTERN OF THE INTERNAL THORACIC ARTERY UNDERGOING CORONARY BYPASS GRAFTING: CONTINUOUS-WAVE DOPPLER ASSESSMENT
}

Raymond Cartier, MD

Omar Semper Dias, MD

Michel Pellerin, MD

Yves Hébert, MD

Yves Leclerc, MD
Surgeons have limited ability to evaluate intraoperatively the patency of internal thoracic artery graft as a bypass for coronary artery revascularization. We used continuous-wave Doppler ultrasonography to study the velocity of the internal thoracic artery before harvesting and after grafting (scanning probe, $8 \mathrm{MHz}$ ). Systolic and diastolic frequency shift (in kilohertz) and systolic frequency/diastolic frequency index were analyzed. Twenty four internal thoracic artery grafts in 15 patients were studied. Fourteen internal thoracic artery grafts were anastomosed to the left anterior descending artery, one to a diagonal artery, and nine to the circumflex artery. The mean systolic frequency before harvesting was 1.19 $\pm 0.40 \mathrm{KHz}$ and no significant differences were found between the right and the left internal thoracic artery (right, $1.17 \pm 0.37$; left, $1.19 \pm 0.42 \mathrm{KHz}$ ). There was a $40 \%$ drop in systolic frequency related to the harvesting. Mean systolic frequency decreased after grafting $(1.19 \pm 0.40$ versus $0.87 \pm 0.32$ $\mathrm{KHz} ; \boldsymbol{p}<0.01)$ whereas mean diastolic frequency doubled $(0.32 \pm 0.12$ versus $0.83 \pm 0.4 \mathrm{KHz} ; \boldsymbol{p}<\mathbf{0 . 0 0 1}$ ) and mean diastolic frequency/systolic frequency index increased from $28 \% \pm 11 \%$ to $101 \% \pm 39 \%(p<0.001)$, indicating an increased myocardial vascularization during diastole. No significant difference was found between grafted arteries (left anterior descending versus circumflex). All patients had an uneventful postoperative course and no perioperative myocardial infarction was reported. Doppler flow quantification of internal thoracic artery bypasses may give the surgeon an opportunity to evaluate intraoperatively the physiologic features and patency of the internal thoracic artery before and after coronary artery bypasses. (J Thorac Cardiovasc Surg 1996;112:52-8) lntas nternal thoracic artery (ITA) is universally recognized as the optimal conduit for myocardial revascularization. ${ }^{1,2}$ However, despite its universal acceptance, intraoperative ITA graft patency assessment remains mostly qualitative. Indirect signs of antegrade flow such as distal vascular bed filling or spontaneous electrical myocardial activity at the unclamping of the ITA pedicle are used as indices of patency. However, these do not give the surgeon a direct flow quantification. Traditionally, cardiac and

From the Division of Cardiovascular Surgery, Department of Surgery, Montreal Heart Institute, Montreal, Quebec, Canada.

Received for publication April 10, 1995; accepted for publication August 28, 1995.

Address for reprints: Raymond Cartier, MD, Montreal Heart Institute, 5000 Belanger St., Montreal, Quebec H1T 1C8, Canada.

Copyright (c) 1996 by Mosby-Year Book, Inc.

$0022-5223 / 96 \$ 5.00+0 \quad \mathbf{1 2 / 1 / 6 8 9 0 8}$ vascular surgeons have used an electromagnetic flow probe to evaluate saphenous vein bypasses, with which magnitude of the blood flow is derived from voltage variation of ions flowing across a fixed magnetic field. ${ }^{3}$

During the past 15 years, surgeons have become more familiar with the use of ultrasonography for blood flow evaluation. Continuous-wave Doppler ultrasonography has been commonly used by vascular surgeons for noninvasive evaluation of peripheral vascular disease and also by cardiac surgeons for assessment of coronary artery bypass. ${ }^{4-8}$ Continuous-wave Doppler ultrasonography applies the principle of the Doppler shift described by the physicist and mathematician Christian Johann Doppler (1803-1853). ${ }^{9}$ Instead of producing a magnetic field, the piezoelectric crystal contained inside the Doppler probe transmits an ultrasonic beam that is reflected by the circulating red blood cells. A separate transducer crystal receives the reflected 
sound waves. The velocity of the blood flow is proportional to the frequency shift between transmitted and reflected ultrasonic beam. Contrary to the magnetic flow probe, the ultrasonic flow probe is effective without vessel denudation and only requires a limited access to the vessel circumference. However, continuous-wave Doppler ultrasonography measures flow velocity whereas the electromagnetic "encircling" flowmeter as a result of known cross-sectional area can measure volumetric flow. Therefore the former is not as accurate as the latter. Nevertheless, the continuous Doppler assessment allows systolic and diastolic flow velocity characterization of the ITA flow pattern during a complete cardiac cycle. Native ITAs are predominantly perfused during systole, whereas coronary arteries are mainly perfused during diastole. Evaluation of systolic and diastolic velocity of ITA graft flow may provide the surgeon with a quantitative evaluation of the flow pattern changes as the ITA graft adapts its hemodynamics to the coronary artery circulation and therefore could become useful in determining graft patency.

The purpose of this work was to evaluate intraoperatively the use of continuous-wave Doppler ultrasonographic assessment of ITA phasic flow pattern before harvesting and after coronary artery grafting and to establish its usefulness as a noninvasive means of evaluating ITA graft patency.

\section{Patients and methods}

Population. The study was done in 15 patients undergoing elective coronary artery operation. There were 12 men and 3 women whose ages averaged $60 \pm 7.6$ years $(52$ to 82 years). The majority underwent operation because of isolated coronary artery insufficiency although two patients had concomitant valve operations. A total of 24 ITA grafts were completed. Before operation all patients had New York Heart Association functional class II or III symptoms.

Doppler evaluation. Velocity of the ITA flow was measured first in situ before any dissection and manipulation of the vessel, a second time after the pedicle dissection, and then after completion of the ITA-coronary artery anastomosis once the patient had been weaned off the extracirculatory support. To standardize the experimental conditions, ITA graft Doppler measurement was completed after the patient's condition was hemodynamically stabilized, which included a systolic pressure $100 \mathrm{~mm} \mathrm{Hg}$ or greater, a pulse rate less than 100 beats $/ \mathrm{min}$, a pulmonary wedge pressure less than $20 \mathrm{~cm} \mathrm{H}_{2} \mathrm{O}$, and a body temperature $35^{\circ} \mathrm{C}$ or higher.

The continuous-wave Doppler device used was a Smartdop apparatus (Koven Technology, Inc., St. Louis, Mo.) coupled to an $8 \mathrm{MHz}$ transducer recorder. Systolic and diastolic ITA blood flow velocities were evaluated by quantification of the magnitude of the Doppler shift $(\Delta f)$ recorded in kilohertz. Doppler frequency shift readings were obtained with a probe angle manually maintained at 75 to 80 degrees toward antegrade ITA blood flow. To obtain this orientation with minimal variability, the probe was first perpendicularly oriented to the ITA pedicle and then pulled back by 10 to 15 degrees to face blood flow stream. Recordings were always done on the midsegment of the ITA because phasic flow has been reported to vary along the course of the ITA. ${ }^{10}$ This segment was always easy to reach and required minimal manipulation. Sterile acoustic gel was uniformly used to couple the ultrasonic transducer to the ITA pedicle to decrease air attenuation coefficients. Systolic and diastolic frequency shift values represent peak velocity of each phase of the cardiac cycle.

Coronary artery assessment. All ITA grafts included in the present study were anastomosed to the left coronary artery territory. To quantify vessel runoff, each coronary artery was evaluated according to a standardized scoring system. A score of 1 was attributed to left anterior descending artery (LAD) terminating before or at the apex of the heart. A score of 2 was attributed when the LAD terminated beyond the apex. An additional score of 1 was added for any major diagonal artery connected to the LAD. In a similar fashion, in the case of ITA bypass to the circumflex territory a score of 1 was given for any marginal artery distal to the anastomotic site whose caliber and runoff were surgically accessible.

Clinical assessment. After the surgical procedure, the patient's postoperative course was evaluated according to routine hemodynamic and cardiac assessment. Perioperative myocardial creatine kinase activity (CK-MB) 1 and 16 hours after operation (normal range, 0 to $30 \mathrm{IU} / \mathrm{L}$ ), ventricular arrhythmia necessitating treatment, and New York Heart Association functional class at hospital discharge were recorded. Perioperative myocardial infarction (MI) was diagnosed by a new $\mathrm{Q}$ wave and CK-MB count greater than $100 \mathrm{IU} / \mathrm{L}$.

Data analysis. Results are expressed as mean and standard error of the mean. Statistical analysis of the data was done by one-way analysis of variance for intergroup observations. Paired Student's $t$ test was used for betweensubject paired observations. Results were considered significant for a $p$ value less than 0.05 .

\section{Results}

Evaluation before and after harvesting. The average systolic and diastolic frequency shifts assessed in situ before harvesting were, respectively, $1.19 \pm$ 0.40 and $0.32 \pm 0.12 \mathrm{KHz}$ and were comparable for both right and left ITAs (Table I). Systolic frequency significantly dropped after harvesting, but the diastolic/systolic ratio remained stable, indicating that the blood flow pattern was not affected (Table II).

Evaluation after grafting. The ITA systolic frequency significantly decreased from $1.19 \pm 0.40$ to $0.87 \pm 0.32 \mathrm{KHz}(p<0.01)$ after coronary artery grafting once patients were weaned off cardiopul- 
Table I. Average Doppler shift frequency of ITA during systole and diastole before harvesting

\begin{tabular}{lccc}
\hline & \multicolumn{2}{c}{ Frequency $(\mathrm{KHz})$} & D/S \\
\cline { 2 - 3 } & Systole & Diastole & (\%) \\
\hline Total $(n=24)$ & $1.19 \pm 0.40$ & $0.32 \pm 0.12$ & $28 \pm 11$ \\
Left $(n=14)$ & $1.19 \pm 0.42$ & $0.32 \pm 0.40$ & $28 \pm 14$ \\
Right $(n=10)$ & $1.17 \pm 0.37$ & $0.31 \pm 0.09$ & $27 \pm 4$ \\
\hline
\end{tabular}

Results are expressed as mean plus or minus standard error of the mean. $D / S$, Diastolic/systolic frequency ratio; $n$, number of vessels evaluated.

monary bypass. In contrast, diastolic frequency increased drastically from $0.32 \pm 0.12$ to $0.83 \pm 0.4$ $\mathrm{KHz}(p<0.001)$, which was reflected also by an increase of the diastolic/systolic frequency ratio $(28 \% \pm 11 \%$ to $101 \% \pm 39 \%, p<0.001)$, indicating a significant change in the pattern of ITA blood flow (Fig. 1). Fig. 2 illustrates an example of a right $(A)$ and left $(B)$ ITA assessment as recorded in situ, after pedicle dissection, and after grafting. As pointed out, in both cases the diastolic frequency shift increased considerably once the graft was submitted to the coronary vascular network and even occasionally overrode the systolic one (as seen in Fig. 2 with the right ITA).

Coronary anatomy. Site of revascularization (LAD or circumflex territory) affected neither systolic $(\mathrm{LAD}, 0.89 \pm 0.32$, versus circumflex, $0.88 \pm$ $\left.0.30 \mathrm{KHz}, p=\mathrm{NS}^{*}\right)$ nor diastolic (LAD, $0.85 \pm 0.30$ $\mathrm{KHz}$, versus circumflex $0.87 \pm 0.50 \mathrm{KHz}, p=\mathrm{NS}$ ) frequency shift. Similarly, the distal runoff, as characterized by the coronary score, did not affect the velocity pattern. Even though a better diastolic score was observed in vessels with larger runoff (scores of 2 and 3), this did not reach statistical significance (Fig. 3).

Postoperative follow-up. All patients had an uneventful postoperative course. No perioperative MI was recorded on routine electrocardiography and cardiac isoenzyme (CK-MB) values remained less than the critical level for $\mathrm{MI}$ in our institution at 1 hour (44 $\pm 17 \mathrm{IU} / \mathrm{L}$, maximum, $80 \mathrm{IU} / \mathrm{L})$ and 16 hours ( $23 \pm 9 \mathrm{IU} / \mathrm{L}$; maximum, $36 \mathrm{IU} / \mathrm{L})$.

\section{Discussion}

The pulsatile aspect of coronary blood flow has been recognized since the seventeenth century. ${ }^{11}$ The arterial and venous flows are generally out of phase, which indicates a change in intramyocardial blood volume during the heart cycle. ${ }^{12,13}$ The arte-

*Not significant.
Table II. Systolic and diastolic Doppler shift frequencies before and after pedicle harvesting $(n=24)$

\begin{tabular}{lccc}
\hline & Before & After & $p$ Value \\
\hline Systolic (KHz) & $1.19 \pm 0.40$ & $0.70 \pm 0.19$ & $<0.01$ \\
Diastolic (KHz) & $0.32 \pm 0.12$ & $0.23 \pm 0.08$ & NS \\
D/S (\%) & $28 \pm 11$ & $28 \pm 11$ & NS \\
\hline
\end{tabular}

$n$, Number of vessels evaluated; $D / S$, diastolic/systolic frequency ratio; $N S$, not significant.

rial blood flow decreases during systole whereas venous blood flow increases. These changes appear mostly related to changing stiffness of the heart muscle, rather than pressure in the pumping chamber of the heart, although controversy still exists. ${ }^{14-16}$ Coronary blood flow pattern is more affected in the left than the right coronary arteries. Right coronary artery flow follows the aortic pressure during systole in contrast to left coronary arterial flow that is submitted to "systolic inhibition." ${ }^{\text {"17 }}$ Experimentally, these differences are abolished when the right side of the heart is facing pulmonary hypertension, which supports the cavity pressure concept.

Other experimental evidence suggests that the myocardial tissue pressure decreases from ventricular pressure in the subendocardium to atmospheric pressure in the subepicardium, explaining the subendocardial flow reduction observed in vivo. ${ }^{18,19}$ Noninvasive evaluation of coronary blood flow has confirmed the biphasic pattern of these arteries. ${ }^{20}$ On Doppler echocardiography blood flow in the LAD displays a monophasic peak in early systole followed by a rapid falling, the former corresponding to the first heart sound and the latter to the second heart sound. Diastole is characterized by an abrupt increase, maximal in early diastole, that gradually decreases thereafter.

The predominant diastolic flow pattern of the ITA graft supplying the coronary arterial network has been previously recognized. ${ }^{7,21}$ By Doppler assessment, the in situ ITA is mainly perfused during systole, as shown in our study, and displays a high resistance flow velocity pattern (strong systolic peak, negative or absent protodiastolic velocity, and low diastolic peak). Once grafted to the left coronary network, the ITA flow pattern instantly adapts to the left ventricular hemodynamics. As shown in Fig. 1, the Doppler shift frequency drops during systolic phase and becomes more prominent during diastolic phase as left ventricular and wall tension 


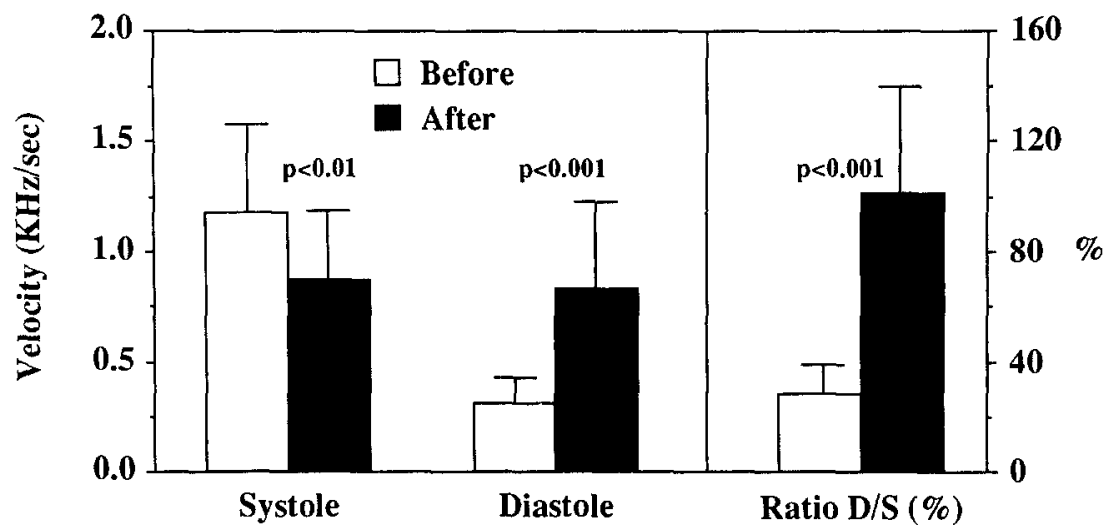

Fig. 1. ITA Doppler shift assessment during systolic and diastolic phases of cardiac cycle before grafting (open bars) and after coronary bypass (closed bars). Significant drop was seen during systole whereas significant increase was recorded during diastole. Diastole-to-systole ratio (ratio $D / S$ ) was also significantly increased.
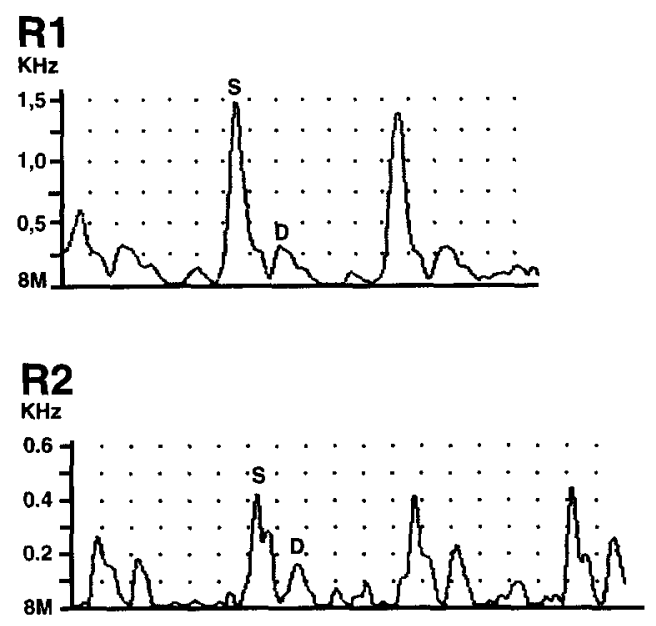

\section{R3}

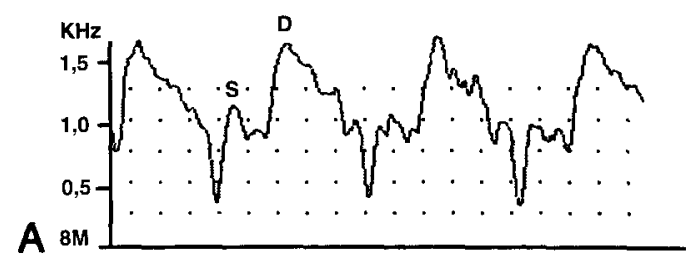

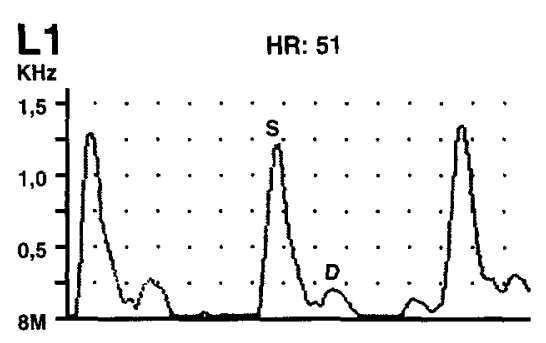
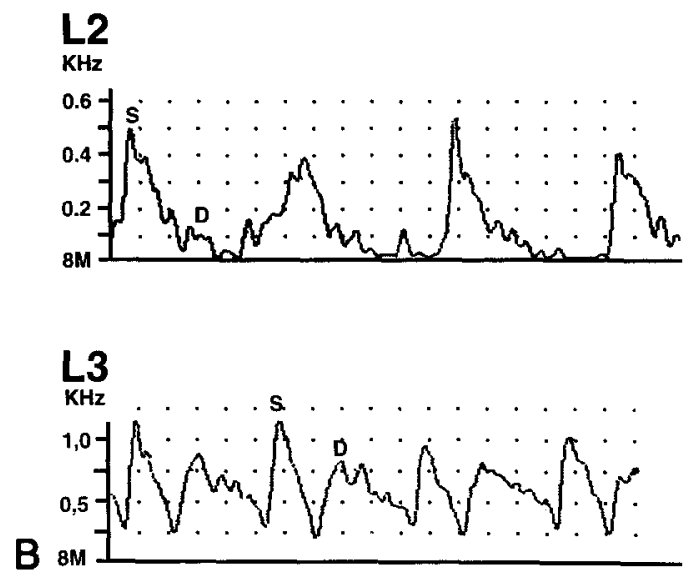

Fig. 2. Illustration of in vivo Doppler shift assessment of right (A) and left (B) ITA before harvesting (1), after harvesting (2), and after coronary bypass (3). Right $(R)$ ITA was anastomosed to LAD and left $(L)$ ITA to circumflex marginal artery. See text for explanation. $S$, Systole; $D$, diastole; $H R$, heart rate.

decreases. This "diastolization" of the ITA blood flow is also related to the low resistance and large capacitance of the coronary artery network and to the ITA self-regulated property on vascular tone. Fusejima and associates, ${ }^{22}$ combining two-dimensional and Doppler echocardiography, compared postoperative hemodynamics of saphenous vein and ITA coronary bypass grafts to the LAD. They found a higher diastolic velocity with ITA graft compared with saphenous vein graft, suggesting a smoother flow pattern with no stagnation with the former conduit. They attributed this observation to a better 


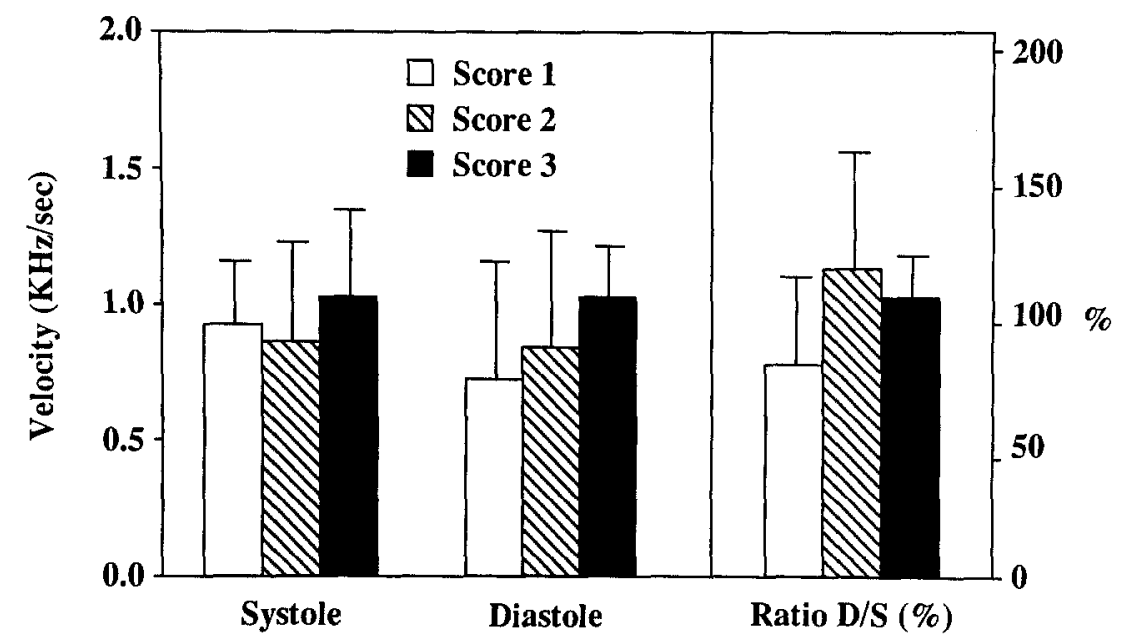

Fig. 3. ITA Doppler shift after coronary artery bypass according to distal coronary runoff. No significant difference was seen between systole and diastole and diastole-to-systole ratio (ratio $D / S$ ).

caliber match between the ITA graft and the coronary artery.

Compared with the saphenous vein, the intima of the ITA releases larger amounts of endotheliumderived relaxing factor, such as nitric oxide, which accounts for the vasodilating capacity of this conduit. ${ }^{23}$ In large arteries, endothelial cells mediate flow-dependent release of endothelium-derived relaxing factor, then initiate a self-dependent compensatory mechanism in situations of increased needs. ${ }^{24,25}$ Clinically, it has been reported that the ITA grafts could adjust their diameter to coronary blood flow demand. ${ }^{26}$ Our observations also confirm that, under resting conditions, right and left ITA flow patterns are quite constant from one patient to another. Surgical dissection significantly affects ITA flow as shown by a $40 \%$ drop in systolic frequency although the phasic pattern remains unaffected. This is mostly caused by side branch ligations and distal vasospasm during manipulation. This also reflects the clinical observation of a decreased ITA free blood flow after dissection that is normally overcome by the use of vasodilating agents. ${ }^{3}$

Neither the runoff score nor the vascular network (LAD versus circumflex) affected the ITA velocity after grafting, although a trend toward better diastolic flow was seen with a higher score. De Bono and colleagues, ${ }^{27}$ assessing ITA to coronary artery graft blood flow by transcutaneous ultrasonography, reported similar observations. They found a positive correlation between ITA graft flow velocity and quality of coronary arterial bed, confirming again the dynamic physiologic adaptability of the ITA. ${ }^{27}$ Nasu and colleagues ${ }^{10}$ have suggested that systolic velocity peak depends on ITA pedicle side branches and consequently is less affected than diastolic velocity by the coronary flow. The variable amount of side branches left after pedicle dissection may account for the systolic Doppler shift variability observed from one conduit to another (as shown in Fig. 2, $A$ and $B$ ). Analyzing phasic flow patterns, Bandyk and associates ${ }^{21}$ showed that anastomotic stricture or pedicle torsion were identified by low or absent diastolic flow whereas ITA vasospasm was associated with a sustained high-velocity flow during the cardiac cycle.

Clinical outcome was excellent for all of our patients. However, because no routine coronary arteriography was done, one cannot extrapolate the predictive value of these observations on long-term patency. Nevertheless, considering an average probe angle of 75 degrees (such a wide angle had to be used to ensure optimal probe contact with ITA pedicle) and an average diastolic frequency of 0.83 $\mathrm{KHz}$, we can estimate an average flow velocity of 32 $\mathrm{cm} / \mathrm{sec}$, which approximates the LAD velocity of $33.5 \pm 5.1 \mathrm{~cm} / \mathrm{sec}$ found by Fusejima ${ }^{20}$ in normal subjects. Because the velocity pattern in native recipient LAD and ITA graft has been reported to be quite comparable we may conclude that the value found in our study truly reflects a normal ITA graft flow (appendix). Consequently, despite its limitation, Doppler frequency shift assessment of the coronary phasic flow may provide the surgeon with a 
valuable piece of information on ITA to coronary artery bypass physiologic conditions by allowing evaluation of ITA patency before harvesting and of ITA graft patency after coronary revascularization. Other authors have used pulsed Doppler ultrasonography coupled to a vessel cuff to evaluate ITA to coronary artery bypass flow with good success. ${ }^{28}$ The use of a cuff allows direct flow measurement although more ITA dissection and manipulation are needed. The continuous Doppler apparatus we used in the study is a simple and inexpensive piece of equipment that can be used by vascular and cardiac surgeons and does not necessitate any ITA dissection. The velocity quantification through the Doppler shift frequency obtained is valuable complementary information to clinical evaluation.

In conclusion, intraoperative assessment of ITA grafts before and after coronary bypass by continuous Doppler assessment is a useful noninvasive technique. It allows phasic quantification of the ITA graft flow pattern and a better understanding of myocardial physiologic processes. It may help in detecting preexisting pathologic conditions of the ITA and intraoperative technical errors.

\section{REFERENCES}

1. Galbut DL, Traad EA, Dorman MJ, et al. Twelve-year experience with bilateral internal mammary artery grafts. Ann Thorac Surg 1985;40:264-70.

2. Barner HB, Standeven JW, Reese J. Twelve-year experience with internal mammary artery for coronary artery bypass. $\mathbf{J}$ Thorac Cardiovasc Surg 1985;90:668-75.

3. Louagie YAG, Haxhe J-P, Buche M, Schoevaerdts J-C. Intraoperative electromagnetic flowmeter measurements in coronary artery bypass grafts. Ann Thorac Surg 1994;57:35764.

4. Beard JD, Scott DJA, Evans JM, Skidmore R, Horrocks M. A Doppler flowmeter for use in vascular surgery. Proc Biol Eng Soc 1988;4:6-12.

5. Simpson IA, Spyt TJ, Wheatley DJ, Cobbe SM. Assessment of coronary artery bypass graft flow by intraoperative Doppler ultrasound technique. Cardiovasc Res 1988;22: 484-8.

6. Bandyk DF, Galbraith TA, Haasler GB, Almassi GH. Blood flow velocity of internal mammary artery and saphenous vein grafts to the coronary arteries. J Surg Res 1988;44:342-51.

7. van der Meulen J, van Son JAM, van Asten WNJC, Skotnicki SH, Lacquet LK. Intraoperative Doppler spectrum analysis of blood flow in the internal mammary artery used for myocardial revascularization. Thorac Cardiovasc Surg 1991; 39:281-3.

8. Fujiwara T, Kajiya F, Kanazawa S, et al. Comparison of blood-flow velocity waveforms in different coronary artery bypass grafts: sequential saphenous vein grafts and internal mammary artery grafts. Circulation 1988;78:1210-7.
9. Doppler C. Uber das farbige Licht der Doppelsterne und einiger anderer Gestirne des Himmels. Prague: Abhandinger der koniglichen bohmischer Gesellschaft der Wissenschafter, 1842:465.

10. Nasu M, Akasaka T, Okazaki T, et al. Postoperative flow characteristics of left internal thoracic artery grafts. Ann Thorac Surg 1995;59:154-62.

11. Scaramucci J. De motu cordis, theorema sextum. In: Theoremata familiara de physico-medicis lucubrationibus Iucta leges mecanicas. 1695:70-81.

12. Sabiston DC Jr, Gregg DE. Effect of cardiac contraction on coronary blood flow. Circulation 1957;15:14-20.

13. Spaan JAE, Bruinsma P, Laird JD. Coronary flow mechanics of the hypertrophied heart. In: Terkeurs HEJD, Schipperheijn JJ, eds. Cardiac left hypertrophy. Dordrecht, The Netherlands: Martinus Nijhoff, 1983:171-201.

14. Krams R, Sipkema P, Zegers J, Westerhof N. Contractility is the main determinant of coronary systolic flow impediment. Am J Physiol 1989;257:H1936-44.

15. Krams R, Sipkema $P$, Westerhof N. Varying elastance concept may explain coronary systolic flow impediment. Am J Physiol 1989;257:H1471-9.

16. Spaan JAE, Breuls NPW, Laird JD. Diastolic-systolic coronary flow differences are caused by intramyocardial pump action in the anesthetized dog. Circ Res 1981;49:584-93.

17. Lowensohn HS, Khouri EM, Gregg DE, Pyle RL, Patterson RE. Phasic right coronary artery flow in conscious dogs with normal and elevated right ventricular pressures. Circ Res 1976;39:760-6.

18. Arts T, Veenstra PC, Reneman RS. Epicardial deformation and left ventricular wall mechanics during ejection in the dog. Am J Physiol 1982;243:H379-90.

19. Heineman FW, Grayson J. Transmural distribution of intramyocardial pressure measured by micropipette technique. Am J Physiol 1985;249:H1216-23.

20. Fusejima K. Noninvasive measurement of coronary artery blood flow using combined two-dimensional and Doppler echocardiography. J Am Coll Cardiol 1987;10:1024-31.

21. Bandyk DF, Galbraith TA, Haasler GB, Almassi GH. Blood flow velocity of internal mammary artery and saphenous vein grafts to the coronary arteries. J Surg Res 1988;44:342-51.

22. Fusejima K, Takahara Y, Sudo $Y$, et al. Comparison of coronary hemodynamics in patients with internal mammary artery and saphenous vein coronary artery bypass grafts: a noninvasive approach using combined two-dimensional and Doppler echocardiography. J Am Coll Cardiol 1990; $15: 131-9$

23. Lüscher TF, Diederich D, Siebenmann R, et al. Difference between endothelium-dependent relaxation in arterial and in venous coronary bypass grafts. N Engl J Med 1988;319:462-7.

24. Kaiser L, Hull SS, Sparks HV Jr. Methylene blue and ETYA block flow-dependent dilation in canine femoral artery. Am J Physiol 1986;250:H974-81.

25. Kaiser L, Sparks HV Jr. Mediation of flow-dependent arterial dilation by endothelial cells. Cire Shock 1986;18: 109-14.

26. Singh RN, Beg RA, Kay EB. Physiological adaptability: the secret of success of the internal mammary artery grafts. Ann Thorac Surg 1986;41:247-50.

27. De Bono DP, Samani NJ, Spyt TJ, Hartshorne T, Thrush AJ, Evans DH. Transcutaneous ultrasound measurement of 
blood-flow in internal mammary artery to coronary artery grafts. Lancet 1992;339:379-81.

28. Louagie YAG, Haxhe JP, Jamart J, Buche M, Schoevaerdts JC. Intraoperative assessment of coronary artery bypass grafts using a pulsed Doppler flowmeter. Ann Thorac Surg 1994;58:742-9.

\section{Appendix}

Velocity (V) is obtained by the equation

$$
\mathrm{V}=\frac{C \times \Delta f}{2 f_{0} \times \operatorname{Cos} \theta}
$$

where $C$ is the sound velocity $\left(1.56 \times 10^{5} \mathrm{~cm} / \mathrm{sec}\right)$ in blood, $\Delta f$ the Doppler shift in kilohertz (0.83), fo the transmitted frequency by the probe $\left(8 \times 10^{3} \mathrm{KHz}\right)$, and $\theta$ the angle at which sound beam intersects velocity vector ( 75 degrees). Then

$$
\mathrm{V}=\frac{\left(1.56 \times 10^{5} \mathrm{~cm} / \mathrm{sec}\right) \times(0.83 \mathrm{KHz})}{2 \times\left(8 \times 10^{3} \mathrm{KHz}\right) \times\left(\operatorname{Cos} 75^{\circ}\right)}=32 \mathrm{~cm} / \mathrm{sec}
$$

(Kempczinski RF, Yao JST, eds. Practical noninvasive vascular diagnosis. 2nd ed. Chicago, London, Boca Raton: Year Book Medical Publishers, 1987:44-55).

\section{Availability of Journal back issues}

As a service to our subscribers, copies of back issues of The Journal of Thoracic and Cardiovascular Surgery for the preceding 5 years are maintained and are available for purchase from Mosby until inventory is depleted at a cost of $\$ 13.50$ per issue. The following quantity discounts are available: $25 \%$ off on quantities of 12 to 23, and one third off on quantities of 24 or more. Please write to Mosby-Year Book, Inc., Subscription Services, 11830 Westline Industrial Drive, St. Louis MO 63146-3318, or call 800-453-4351 or 314-453-4351 for information on availability of particular issues. If unavailable from the publisher, photocopies of complete issues may be purchased from UMI, 300 N. Zeeb Rd., Ann Arbor, MI 48106, 313-761-4700. 